\title{
LANGUAGE LEARNERS’ BEHAVIOUR AT MULTINATIONAL COMPANIES
}

\author{
Szilvia Szabó \\ Marketing and Tourism Institute, Faculty of Economics, University of Miskolc, Miskolc, \\ Hungary \\ szszabo@szabonyelviskola.hu
}

\begin{abstract}
In our digitalized world, foreign language skills are becoming vital in the life of multinational companies. In addition to traditional teaching methods, online teaching methods play an important role in language teaching. In this paper we try to compare the perceived effectiveness of online and offline teaching methods. We also aim to understand language learners' behaviour, including their motivation, service provider choice, information sources considered in their choice and their willingness to pay. In this paper, we also examine the extent to which language learners are supported in everyday company teaching by the Eflow by SZABO online software, which can be used in a flexible form of education. A combined (online and paper-based) survey was conducted among language school students who are using Eflow by SZABO. To analyse the data, we have used descriptive statistics and factor analysis. We have found that language schools are considered to be the most effective form of language learning, closely followed by Eflow by SZABO. Individual learning is also seen as being more effective than learning in groups. The findings can be used by scholars and in throughout language teaching business too.
\end{abstract}

Keywords: online language learning; traditional language learning; consumer behaviour; effectiveness; multinational company; Eflow by SZABO.

JEL classification: M31; Z13.

\section{Introduction}

Because of their busy schedules and a dearth of acceptable language-learning opportunities, many learners in Hungary find it difficult to sit down and force themselves to learn a second or third language. The opportunity to learn online may facilitate learning, partially alleviating these stumbling blocks and providing motivation on the part of learners. A great many of the populace are in possession of a smartphone, which provides the chance for learning and discovery, and has a radical impact on people's habits and interactions in a multitude of milieus (Nagy, 2017). I have taught at language courses at different multinational companies for a long time. Consequently, it is very important for me to continuously monitor the special demands of this market and to understand these demands in order to be able to react to any change at the right time.

Now we would like to take a step further by proactively looking for the hidden demands of this market segment.

\section{Literature review}

Before the current IT explosion, the use of this technology was quite restricted. Now, by contrast, we can see a much more flexible application owing to the proliferation of digital tools, mobile technology, and collaborative systems. The horizons of language acquisition are broadening at a furious pace. 
Motallebzadeh, K., Ahmadi, F., Hosseinnia, M. (2018) analysed teachers' creativity and their teaching effectiveness, and they found that the more creative someone is the more creative they are when teaching a language. The study points out that there is a significant difference between female and male teachers with regards to the creativity of their teaching in favour of women.

Blended learning can use many different types of forms and methods in foreign language teaching. Online learning contents, surpassing the limits of formal education, contain many visual elements, listening texts and video files. Many people would like to try a blended language course provided at just a fraction of the price of traditional language courses.

With the development of the digital world, more and more tools are available for online teaching and they are increasingly becoming part of our everyday life. The continuous use of these tools aid and assist online teaching opportunities in establishing themselves naturally and almost invisibly in our daily routine, thus making them generally accepted. The methodology of online teaching has become more refined and new elements, e.g. gamification elements have been introduced, which enhance students' motivation due to their playfulness.

According to a survey by Jabeen and Thomas (2015), the majority of the respondents say that some years ago they preferred learning with a teacher in a classroom to learning on their own in a computer-assisted environment, but these preferences have changed to a small extent by now. They investigated the learning trends of students who opt for online language courses and their effectiveness by assessing multiple factors, including the use of the latest available technology and the skills that are taught by these online methods. The online teaching of various language skills was examined separately, skill by skill, and the online methods were compared with the traditional classroom methods. They concluded that students consider lessons with a teacher to be more efficient for language learning than in the online environment. They concluded that it is necessary to have the teacher' assistance and support for the proper conduct of online speaking activities. This was true some years ago, but with the rapid advancement of technology it can be stated with confidence now that today's and especially the near future's technical facilities can easily make up for the teacher's physical presence in such cases. Therefore, our opinion is that with time all the positive elements of face-to-face language teaching that seem to be advantageous in several respects will be possible to be replaced by a corresponding digital method. However, Shishavan and Sadeghi (2009) claim that it is essential to have good and qualified teachers so as to make the educational system operate efficiently and to improve the quality of learning.

According to Ghavifekr and Rosdy (2009) ICT (Information and Communications Technology), technology-based teaching is effective for both teachers and students and one important factor of successful learning is that the teachers are well-equipped and wellprepared in terms of technological tools and facilities. "Paperless" Foreign Language Teaching offers an opportunity for students to acquire the necessary information during foreign language lessons by themselves at skill level. Shishkovskaya, Sokolova and Chernaya (2015) found that one of the main advantages of the „paperless” technique is that it increases the motivation of students in learning a foreign language. "There is more information available to any student with a smartphone than an entire empire would have had access to three thousand years ago" (Shishkovskaya, Sokolova, Chernaya, 2015). The main advantages of this technology are that students take an active role in the educational process, they can interactively communicate with their e-learning environment, computerassisted teaching is flexible, the rate and pace of learning can be easily adjusted and controlled, the teaching load, the information provision and its updating can be optimized. Through the use of "paperless" technology the teacher can undergo a creative process together with the students and discover new training techniques and technologies. In this 
article the authors find that with the progress of technical devices not only the teacher's physical presence but also the paperless methods may have a motivating effect. Quick feedback and assessment, the continuous automatic fine-tuning of customisable contents strengthen the acceptability of online systems.

\subsection{Advantages of online language teaching}

Self-regulated time management is the crucial concept here, as online learning offers flexibility for learners in practising or reviewing the foreign language in the timeframe that is suited to their level and style of learning. This provides learners with the independence they need; they need to adjust their schedule only to themselves, as they can spend as little or as much of their time on a particular assignment as they want to. Requiring internet access as a prerequisite, online tools offer total flexibility in time. This stands in stark contrast to oldstyle methods, which are tied to brick-and-mortar venues. Nor do old-school methods offer the savings, in terms of both time and money, as digital ones do, as up-to-date methods can be cheaper than traditional ones, and they obviate the need for spending time in one's car, laboriously going to and from the lessons. Instantaneous transmission of language learning materials and other information, so widely taken for granted today means that the significance of current communication technologies must not be underestimated, neither in teaching nor in other fields.

\subsection{Disadvantages of online language teaching}

Interpersonal teacher-student contact clearly remains a requirement for education, as learners need the backing of another individual to stimulate the timely and quantifiable acquisition of the foreign language. Motivation is the key. Even if online teaching offers great flexibility, the lack of motivation can be one of the main obstacles to language acquisition. Online technology itself does not satisfy all the needs of a language learner. Spoken interaction between people is still unsurpassed in the field of language acquisition, and this element is sadly lacking from IT-driven teaching. At the same time technology appears to be able to offer good solutions for replacing language teachers with regard to both motivation and interpersonal communication, even if to a small extent initially but definitely to a larger extent in the near future.

\section{Eflow by SZABO}

Eflow by SZABO, a fully functioning online application, assists those who set out to develop their teaching materials at corporate language courses. Learners who cannot use their English knowledge at their workplace due to a lack of time but who would still want to refresh or deepen their knowledge previously acquired can engage in the process of language learning. Eflow by SZABO, a entirely online application, also assists those who would like to develop their language skills independently at multinational companies.

The online material was developed for five levels: A1, A2, B1, B2 and C1 in line with the requirements set by the Common European Framework of Reference for Languages. It was developed on the basis of detailed and well-structured training courses and teaching experiences. Participants can choose the following skills: Vocabulary, Grammar, English Usage, Reading Comprehension, Writing, Listening Comprehension and Speaking. The study material package includes 15-23 topics at different levels. Before starting using Eflow by SZABO a preliminary knowledge test is recommended. One topic per week is suggested for acquisition. A mid-term test and a final test can be found in the package, which are intended to increase the language learner's motivation. The study materials are easy to handle and are well-structured. Different skills are indicated with different symbols. 


\section{Methodological Approach}

In order to measure the effectiveness of different language learning forms and understand the language learners' consumer behaviour a combined (online and paper-based) survey with a sample of 58 respondents was conducted in 2019. Exclusively, language learners at multinational companies who are currently using the Eflow by SZABO module were included in the study. All of them were surveyed, but not everybody responded to each question, so the total number of respondents is always indicated if it is less than 58 .

At the multinational companies where SZABO Nyelviskola teaches English in classroom form of language teaching, each student gets a credit as an extra service to the Eflow by SZABÓ online program. So, within a closed system, students can use their credit to develop the skill they choose as they like and as they can fit it into their schedule. The completion of the questionnaire was on a voluntary basis. A total of 124 students were given the option to decide on their own if they wanted to complete the questionnaire related to the research topic of this paper. Eventually, there were 58 language learners who completed the questionnaire voluntarily either online or on paper.

In the survey, we used different self-developed constructs to measure different aspects of the language learners' behaviour. The importance of motives, the importance of information sources used in the decision-making process as well as the importance of attributes of the language service provider choice were measured on a five-point importance scale. The perceived effectiveness of the different types of language learning was measured on a fivepoint effectiveness scale, whereas the development of language skills was measured on a five-point extent scale.

\section{Analysis and Results}

Our results show that respondents consider learning languages as being important. The mean was between important and very important on a five-point scale (4.3). They quite like learning languages. Respondents are quite motivated to learn foreign languages. The primary motive for learning languages is that easier communication with others becomes easier, followed by higher income and obtaining a language certificate. Obtaining a secondary school qualification and working abroad are the weakest motives to learn foreign languages as according to the survey (Figure 1).

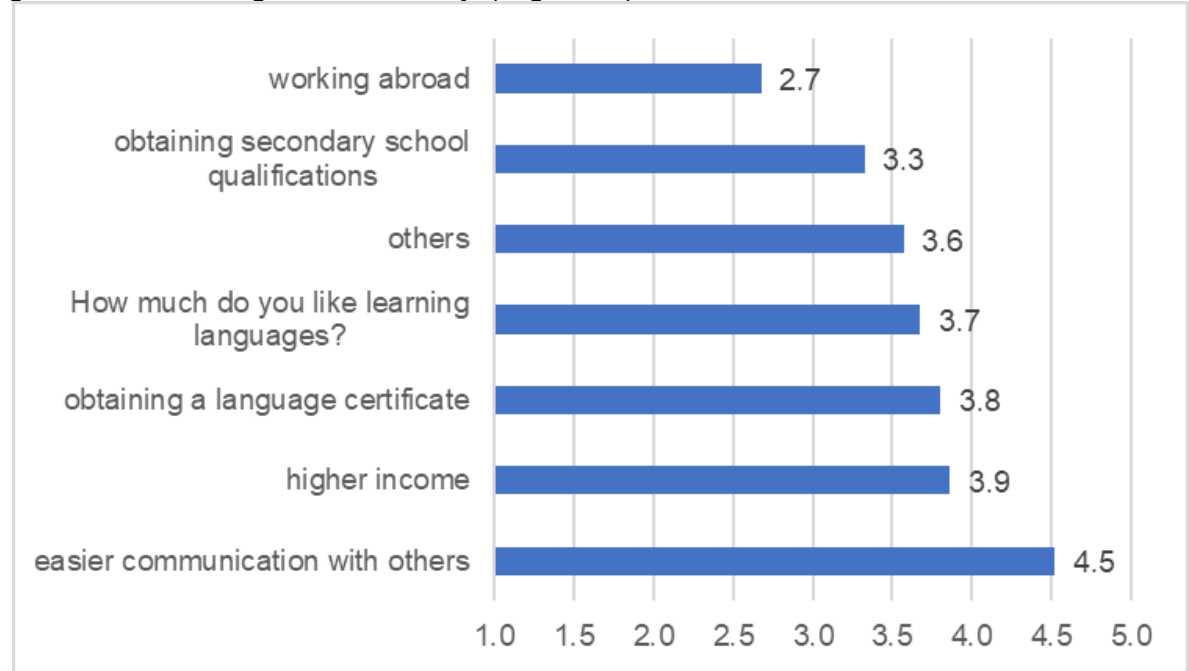

Figure 1 Motives for learning languages $(1=$ the weakest $\ldots 5=$ the strongest) 
As far as the importance of information sources used in the decision-making process of language learning is concerned, friends and acquaintances are found to be the most significant influencing factor, followed by family members, the social media and online advertisements. Other information sources and flyers are regarded as non-important information sources (Figure 2).

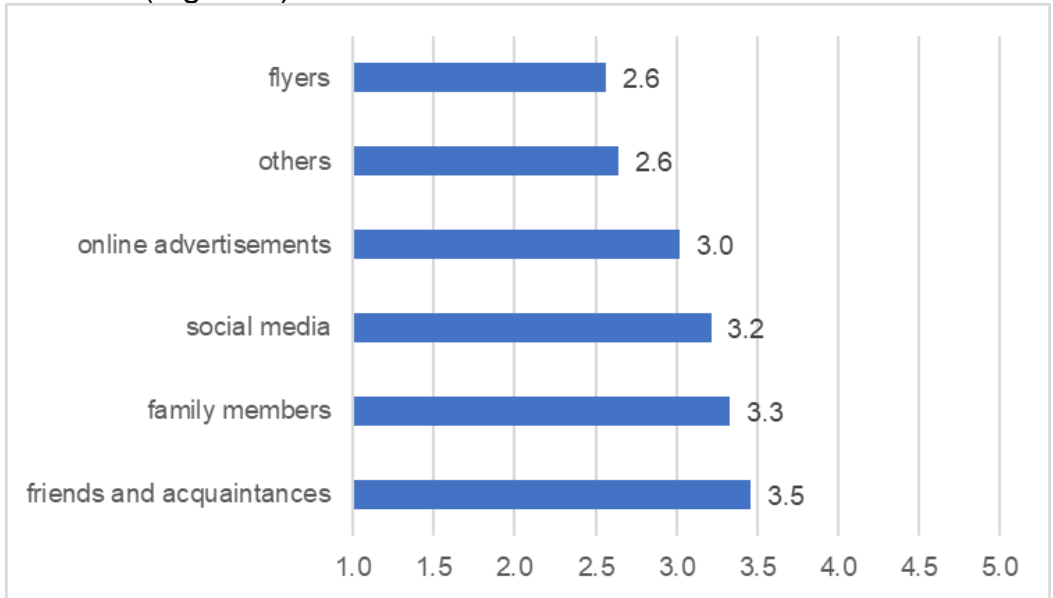

Figure 2 Importance of information sources (1= the least important ...5= the most important)

Figure 3 shows the importance of the attributes of choosing a language learning service provider. Perceived effectiveness of the service provider, services fee, and group size are the key to success or failure, being the most important attributes when it comes to choosing a service provider (i.e. a language school or other forms of language learning). Flexibility of the administrative procedures related to language learning and service environment as well as the image, reputation \& brand name and the ease of use (webpage/app) are equally important attributes. The service provider's accessibility, i.e. the distance from where the potential student resides or works, and parking opportunities are also considered. The design of the language learning website/app is the least important attribute in regards to the decision making process.

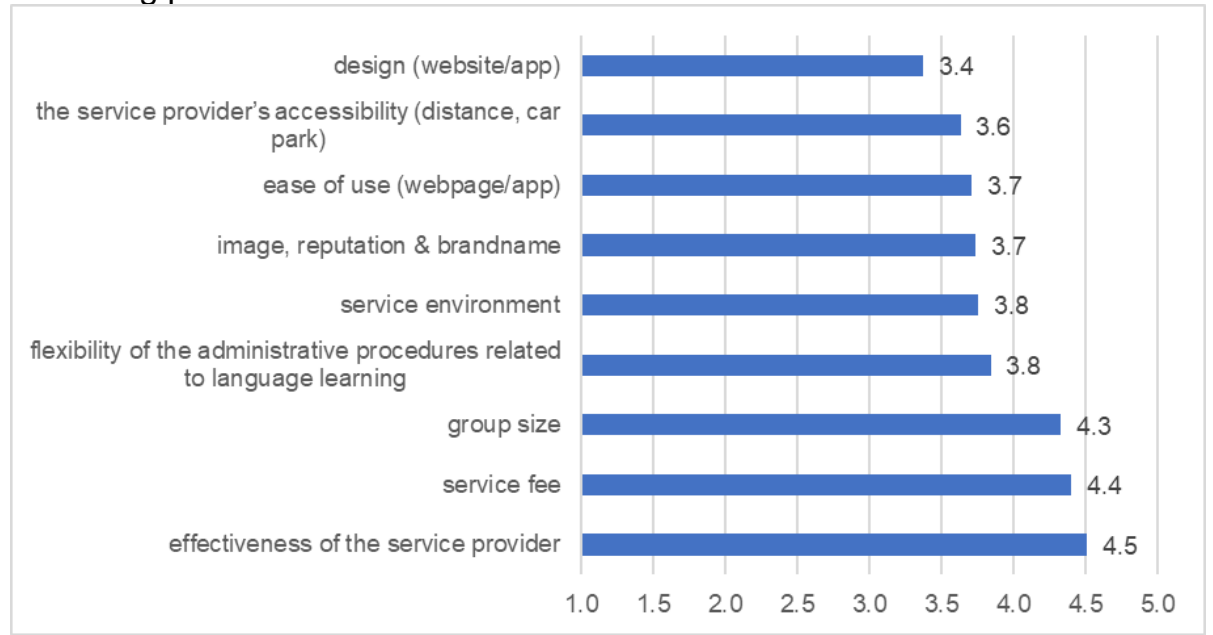

Figure 3 Importance of the attributes of choosing a language learning service provider

Figure 4 shows the Perceived effectiveness of language learning types. It was found that the respondents consider the effectiveness of learning/teaching at a language school as 
being between effective and absolute effective, the mean was 4.5 on a five-point scale, followed by the score given for the effectiveness of Eflow by SZABO, the effectiveness of learning language online, and the effectiveness of language teaching in public education, which is not considered effective at all by the respondents.

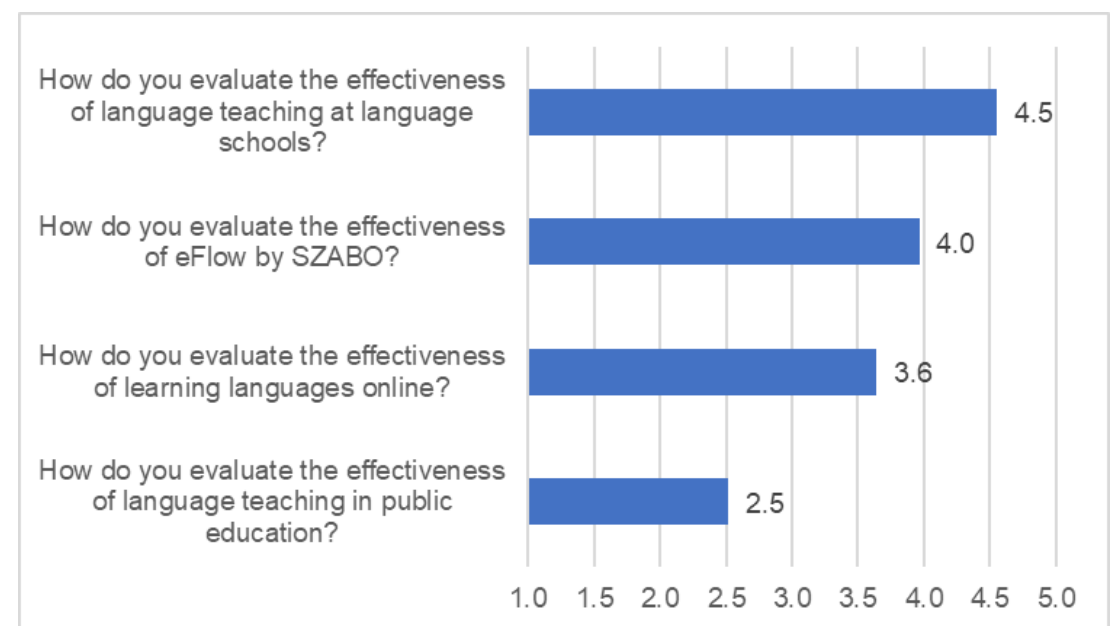

Figure 4 Perceived effectiveness of language learning types

Figure 5 shows the Perceived effectiveness of language learning forms. With regard to the perceived effectiveness of language learning forms, we have found that the respondents consider the individual learning in classrooms (individual offline) to be the most effective form, the mean was 4.0 on a five-point scale. The second most effective learning form was the individual online, followed by the traditional classroom groups. Language teaching in online groups was seen as the most ineffective form of teaching/learning.

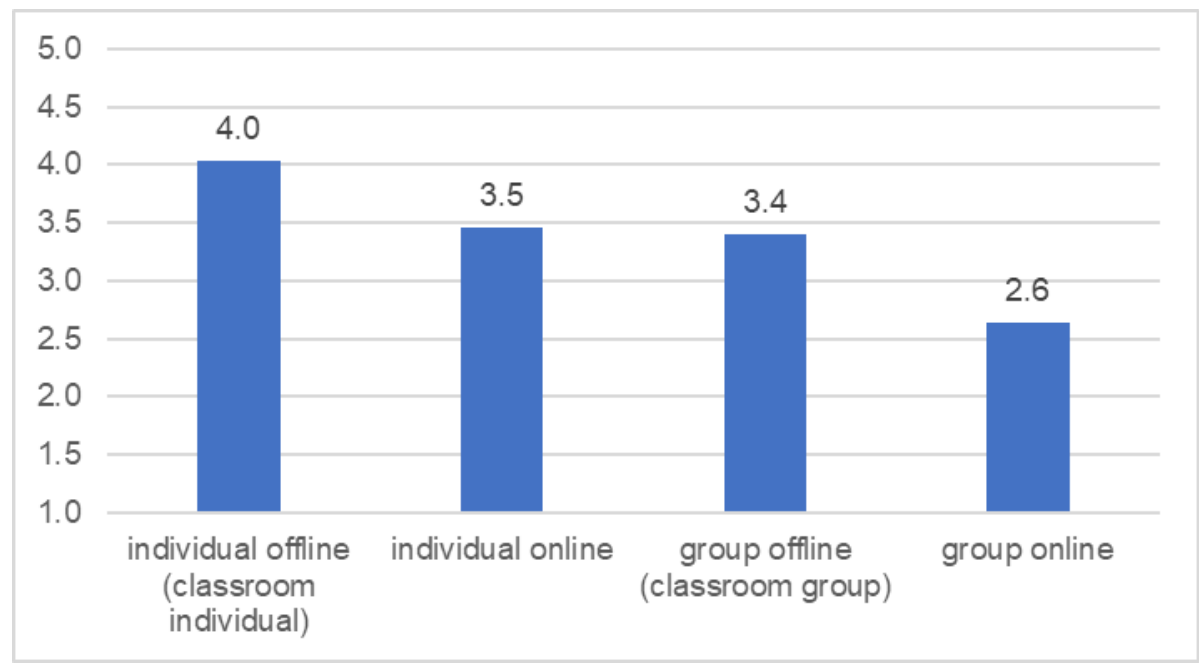

Figure 5 Perceived effectiveness of language learning forms

Figure 6 shows the Willingness to pay. We have found that the respondents are willing to pay the highest amount for individual online learning in the first place, and for classroom 
individual learning in the second. They intend to pay significantly less for learning in traditional classroom groups, and the least for learning in online groups.

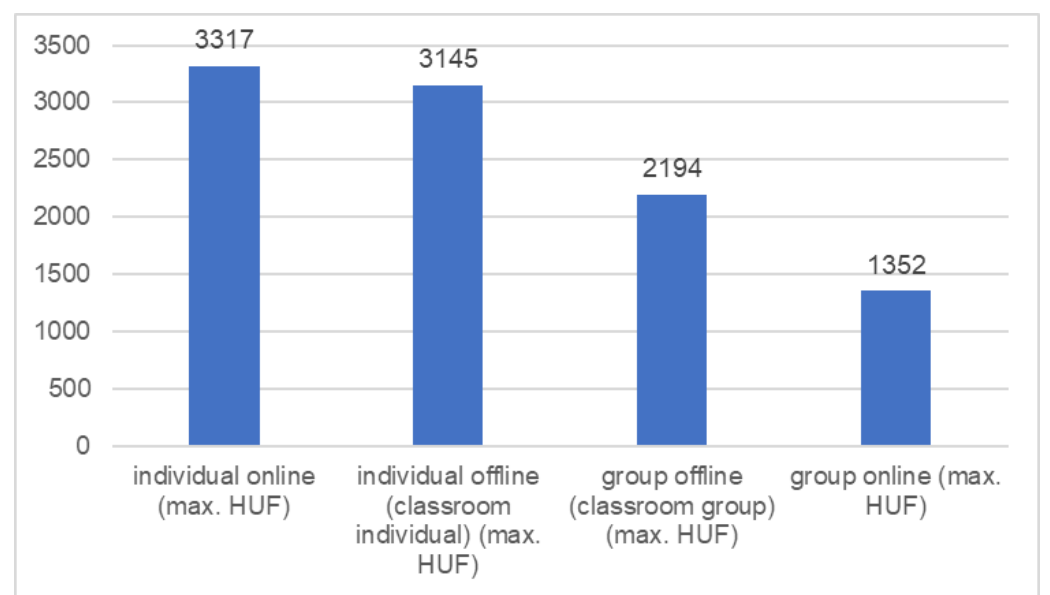

Figure 6 Willingness to pay

Figure 7 shows the Improvement of skills by Eflow by SZABO. Having investigated the improvement of language skills by Eflow by SZABO, we have found that the respondents are of the opinion that their listening skill was improved the most: the mean was 4.0 on a five-point scale. The software also improved their vocabulary skill, speaking skill, reading skill, and their English usage skill. They have stated that their writing and grammar skills were improved the least by Eflow by SZABO.

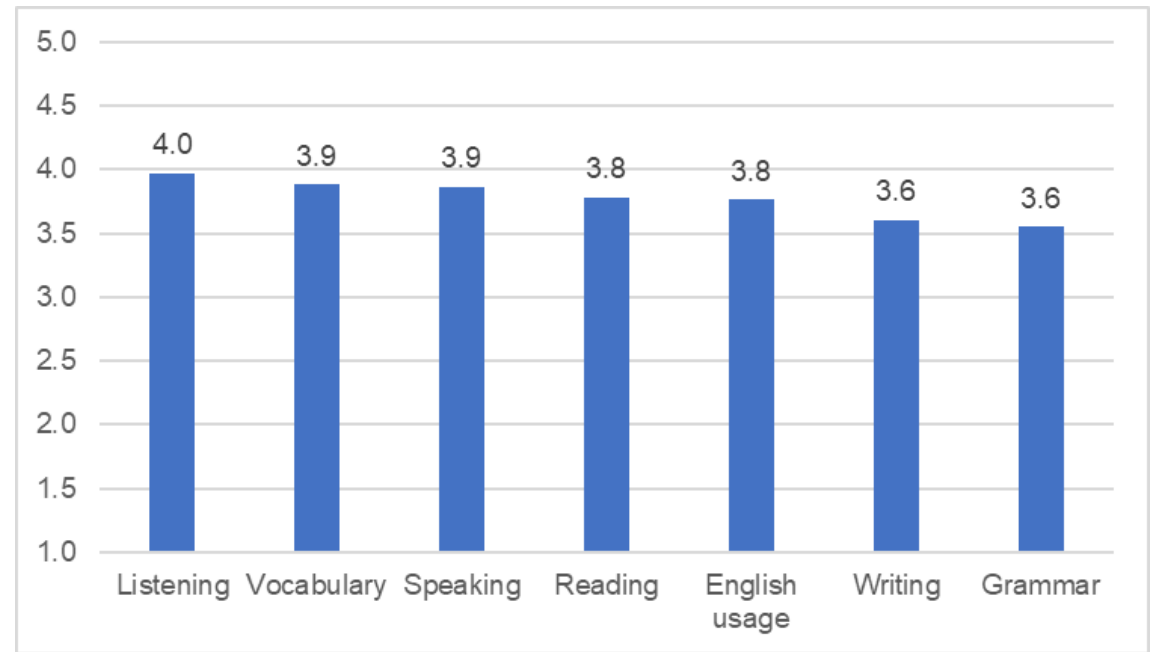

Figure 7 Improvement of skills by Eflow by SZABO

The Kaiser-Meyer-Olkin Measure of Sampling Adequacy $(\mathrm{KMO}=0.738)$ indicates the suitability of the data for further analysis by Kaiser's standard. So does Bartlett's Test of Sphericity (Approx. Chi-Square $=140.265$; $d f=36$, Sig. $=.000$ ). The Principal Component Analysis initially extracts 16 factors, of which there are only three components whose Eigenvalue is at least 1 . They explain $69.92 \%$ of the total variance. The Rotated Component Matrix shows the three resulting factors (Table 1). 
Table 1: Rotated Component Matrix

\begin{tabular}{|l|c|c|c|}
\hline \multirow{2}{*}{} & \multicolumn{3}{l|}{ Component } \\
\cline { 2 - 4 } & $\mathbf{1}$ & $\mathbf{2}$ & $\mathbf{3}$ \\
\hline the service provider's accessibility (distance, car park) & $\mathbf{. 8 3 8}$ & -.005 & .136 \\
\hline ease of use (webpage/app) & $\mathbf{. 7 8 7}$ & .367 & -.014 \\
\hline $\begin{array}{l}\text { flexibility of the administrative procedures related to } \\
\text { language learning }\end{array}$ & $\mathbf{. 7 4 7}$ & .065 & .359 \\
\hline service environment & & & \\
\hline design (website/app) & .725 & .254 & .362 \\
\hline effectiveness of the service provider & .430 & .692 & -.006 \\
\hline image, reputation \& brand name & .211 &. $\mathbf{7 9 3}$ & .020 \\
\hline service fee & -.144 &. $\mathbf{7 8 6}$ & .371 \\
\hline group size & .334 & -.016 & .735 \\
\hline
\end{tabular}

Extraction Method: Principal Component Analysis. Rotation Method: Varimax with Kaiser Normalization. Rotation converged in 6 iterations.

Factor 1 includes the service provider's accessibility (distance, car park), the ease of use of webpage/app, the flexibility of the administrative procedures related to language learning and the service environment, so it is named a Service Soft factor. The design of the service provider's website/app and the perceived effectiveness of the service provider as well as the image/reputation \& brand name of the service are substantially loaded on Factor 2. Therefore, it can be concluded that brand name, image, design and the perceived effectiveness of the language service provider are interrelated in the language learners' mind. Factor 3 is made up of the service fee and the group size. It suggests that language learners' willingness to pay and the group size are also connected.

At the time of writing this paper, no relevant literature was available so we were not in a position to compare the results of the three factors to previous results. Thus, the results of this paper contribute to the literature of this topic.

\section{Conclusions and Implications}

Based on the results of this research, it can be stated that the respondents are quite motivated to learn foreign languages at multinational companies. Having analysed the importance of information sources used in the decision-making process of different forms of language learning, friends and acquaintances are found to be the most significant influencing factor. The effectiveness of the service provider is the most important attribute in choosing a service provider. In comparison to previous times, recognition of the effectiveness of online teaching has become much stronger among language learners. This shows that the tools and methodologies have been improving and digital tools have also been incorporated in language teaching at companies. The other important finding is that companies are open to online teaching insofar as it complements offline teaching to make participants motivated and successful in language learning as much as possible. In other words, the company management supports the development of new technologies and software, which is a long-term condition for staying on the market. It seems from the surveys that methodological preferences are slowly progressing towards realignment, meaning that the respondents consider online learning/teaching almost as effective as face-to-face teaching. In the same time, it is a rather interesting finding that the respondents would be willing to pay more, even if not by much, for online teaching. This confirms that the everyday use of technological tools and the refinement of online solutions are making online language teaching increasingly accepted. 
Our view is that the condition for staying on the market in the long run is to start using appropriate online methods in time in (company) language teaching, and efforts should be made to design these methods so that they strengthen the language learning motivation of learners. It should be achieved that by using new technologies and software that the teacher's role (teacher's direct communication with students) could be replaced in language teaching as early as possible. This could be covered by the slightly higher prices that the market would be willing to pay for such a service and at the same time the personnel costs could also be reduced.

\section{References}

Ghavifekr, S. and Rosdy, W.A.W., 2015. Teaching and Learning with Technology: Effectiveness of ICT Integration in Schools, International Journal of Research in Education and Science, 1 (2), pp. 175, DOI:10.21890/ijres.23596.

Jabeen, S. S. and Thomas, A. J. 2015. The effectiveness of Online Language learning, Proceedings of the World Congress on Engineering and Computer Science 2015, Vol I, WCECS 2015, October 21-23, 2015, San Francisco, USA.

Motallebzadeh, K., Ahmadi, F. and Hosseinnia, M., 2018. The relationship between EFL teachers' reflective practices and their teaching effectiveness: A structural equation modeling approach, Cogent Psychology, 5 (1), doi.org/10.1080/23311908.2018.1424682.

Nagy, S., 2017. "The Role of Country of Origin in Mobile Phone Choice of Generation Y and Z. Journal of Management and Training for Industries, 4 (2), pp. 16-29, DOI: 10.12792/JMTI.4.2.16.

Shishavan, H. B. and Sadeghi, K., 2009. Characteristics of an Effective English Language Teacher as Perceived by Iranian Teachers and Learners of English. English Language Teaching 2(4), 130-143. doi:10.5539/elt.v2n4p130.

Shishkovskaya, J., Sokolova, E. and Chernaya, A. 2015. "Paperless" Foreign Languages Teaching. Procedia - Social and Behavioral Sciences. 206, pp. 232-235. 10.1016/j.sbspro.2015.10.014.

\section{Bio-note}

Szilvia Szabó is a Ph.D. student at Marketing and Tourism Institute, Faculty of Economics at University of Miskolc, Hungary. Szilvia's investigated language learners' behaviour at multinational companies, conducting a study on comparing the perceived effectiveness of online and offline teaching methods. The author, as an owner of a language school, is primarily interested in research in digital marketing, online and traditional language learning, and consumer behaviour. 